\title{
Teatro nas fronteiras: descentralizando o teatro no interior de Mato Grosso
}

Maria Edilene de Jesus ${ }^{1}$

Recebido em: 15/04/202

Aprovado em: 04/05/2020

DOI: $10.5965 / 2358092521232020206$

1 Mestranda em teatro pela Universidade do Estado de Santa Catarina (UDESC). E-mail: edilenerodriguez@hotmail.com 


\section{RESUMO}

Este relato propõe um olhar para o teatro que é feito nas bordas, nas fronteiras das comunidades. Exponho aqui experiências como professora-artista em um teatro realizado na e com a comunidade no interior do Estado de Mato Grosso. Esse olhar visa refletir quais foram os caminhos traçados pelo Teatro Faces para construir e potencializar o teatro na comunidade por meio da descentralização do acesso às ações da Escola de Teatro Faces em Primavera do Leste. Contextualizando a partir de suas poéticas e práticas teatrais para infância e juventude um diálogo com a comunidade, prezando pelos atravessamentos, pela história de vida e de como essas pessoas - aprendizes da escola de teatro - pensam o mundo.

Palavras-chave: teatro na comunidade, Escola de Teatro Faces, contextos teatrais no interior de Mato Grosso, teatro para infância e juventude, ensino de teatro.

\section{ABSTRACT}

This report proposes a look at the theater that is done at the edges, at the borders of the communities. I discuss here experiences as a teacher-artist in a theater held in and with the community in the interior of the State of Mato Grosso. This look aims at reflecting on the paths traced by Teatro Faces to build and enhance the theater in the community through the decentralization of access to the actions of the High School Faces Theater in Primavera do Leste. Contextualizing a dialogue with the community based on their poetics and theatrical practices for children and youth, valuing the crossings, the history of life and how these people - theater school apprentices - think the world.

Keywords: theater in communities, High School Faces Theater, context theater in the interior of the state of Mato Grosso, theater for children and youth, theater's teaching. 


\section{DA FRONTEIRA À POROSIDADE DO TEATRO NA COMUNIDADE}

O teatro feito nas fronteiras, nas brechas da sociedade realizado pela comunidade se torna relevante e potente para os estudos da pedagogia do teatro por quebrar estruturas e tornar visível a experiência e realidade do teatro de grupo e do teatro na comunidade presente nos quatros cantos do Brasil. A acepção do termo fronteira vai de encontro à reflexão sobre as condições de produção e circulação do teatro que busca um espaço político vital que se faz na margem do sistema, isto é, que pensa e gera relatos a partir de outros lugares fora do eixo Rio-São Paulo.

Aqui, traço uma linha poética por meio de relatos das minhas experiências como professora-artista, fruto do teatro realizado na e com a comunidade no interior do Estado de Mato Grosso, o qual se engaja em levar sua arte para todo o território brasileiro por intermédio de políticas públicas de descentralização e potencialização das artes da cena.

A arte que pulsa em Primavera do Leste é a arte que se faz potente em cada criança, adolescente e adulto que passou pelas gerações do Teatro Faces e hoje deixam terreno fértil para a emancipação de um dos maiores projetos de teatro do Estado de Mato Grosso.

O Grupo de Teatro Faces ${ }^{2}$ foi fundado em 20 de março de 2005 por Wanderson Lana com intuito de construir uma cena teatral, ainda inexistente, em Primavera do Leste, cidade de apenas 34 anos de emancipação política e 62.000 mil habitantes. 0 grupo ainda mantém em seu corpo sua primeira formação de artistas e está formando sua terceira geração por meio da Esco-

20 Teatro Faces foi idealizado pelo historiador, dramaturgo, diretor, ator, mestre e doutorando em culturas contemporâneas pela Universidade Federal de Mato Grosso, Wanderson Alex Moreira de Lana. Hoje atual secretário de Cultura, Turismo, Lazer e Juventude de Primavera do Leste - MT. Vencedor do último prêmio Funarte de Dramaturgia com o texto “Ensaio sobre a Verdade" 2018. 
la Municipal de Teatro - Projeto: Teatro Faces.

Outro aspecto a ser ressaltado é que o grupo era composto, inicialmente, por aproximadamente 23 pessoas, entre crianças, jovens e adolescentes que variavam entre 11 a 20 anos de idade - grande parte advindos de comunidades periféricas - isto é, aos 11 anos de idade eu ingressava como uma das fundadoras do grupo - mesmo sem saber - e iniciava, assim, minha trajetória de atriz, futura professora e pesquisadora das artes da cena.

Assim, como grande parte de grupos de teatro em comunidades, o Teatro Faces, no início de sua trajetória não tinha um local adequado para os ensaios, portanto, usava a Escola Getúlio Dornelles Vargas, nos intervalos entre os turnos vespertino e noturno como espaço de ensaio. Quando não era possível usar o espaço da escola, o grupo se reunia na praça do centro da cidade ou na varanda da casa de alguém. Sem sabermos, já estávamos modificando o espaço urbano e estabelecendo relações com os transeuntes, sobretudo, friccionando fronteiras e consolidando a prática teatral nos espaços da comunidade. Para Marcia Pompeo Nogueira (2002, p. 70), "o teatro na comunidade trata-se de um teatro que envolve a comunidade em todo o processo teatral, incluindo a criação do texto e representação que são baseadas em problemas apontados pelos participantes. Em contato com as necessidades do teatro em comunidades, ela argumenta que:

A opção pelo teatro em comunidades surge, para alguns, como evolução de uma prática teatral, que busca uma interação com um contexto específico, para outros, surge de uma atuação comunitária, que busca no teatro um caminho para ampliar seu vínculo com a comunidade. Tanto num caso como no outro há a necessidade de debater o fazer teatral em comunidades (NOGUEIRA, 2010, p. 17).

Dessa forma, a fim de estabelecer conexões e debater o fazer teatral com o nosso entorno, montamos, sem experiência, nosso primeiro espetáculo Ilusões Negras e levamos para con- 
correr na Mostra Mato-Grossense de Teatro $^{3}$ realizada na cidade de Rondonópolis, neste mesmo estado ainda em 2005. Neste festival o Grupo de Teatro Faces recebeu sua primeira indicação na categoria de Melhor Ator e esta indicação estimulou o grupo a se interessar ainda mais pela área teatral, e passasse a buscar conhecimento através de profissionais da região.

Engendramos, dessa forma, brechas e caminhos para nos conectarmos cada vez mais com o local em que estávamos inseridos, falando sobre nossa gente nos processos cênicos e construindo pontes. Pontes essas que culminaram em uma parceria com a Secretaria Municipal de Educação, Cultura, Esportes e Lazer que nos deu acesso ao espaço do Centro Cultural, o qual era destinado até então apenas para ações de fotografia de modelos (Misses de Primavera do Leste), exposição de quadros e aulas de desenho.

Com o espaço do Centro Cultural, não precisávamos mais usar os intervalos entre as aulas para ensaiar ou a praça da cidade. Estávamos, aos poucos, nos tornando um dos principais grupos de teatro do estado com espetáculos voltados para a infância e juventude, evidenciando em nossos trabalhos o Folclore e o imaginário infantil por meio de dramaturgias autorais como afirma Yuri Lima Cabral (2019), um dos membros do grupo:

A companhia ficou conhecida pelo desenvolvimento de processos cênicos, assim como a construção de dramaturgias autorais, que buscam diálogo direto com as comunidades as quais as atrizes e atores estão inseridos, assim como a relação intrínseca com as comunidades indígenas circunvizinhas - xavante, boe-bororo, trazendo para a cena, assim como para a proposta de ensino, a relação e o imaginário destas comunidades, desenvolvendo assim, propostas cênicas voltadas para a infância e juventude que possibilitam um olhar para o seu entorno, assim como a relação social presente nas comunidades (CABRAL, 2019, p. 16).

3 Festival Mato-grossense de Teatro regido pela antiga FEMAT - Federação Mato-grossense de Teatro, a qual se encontrou em crise, com dificuldades ideológicas e financeiras, ocasionando o encerramento de suas atividades no ano de 2010, quando teve a última edição do Festival Mato-grossense de Teatro na cidade de Rondonópolis. 
Por isso, desde o início da trajetória o grupo teve como mote de suas pesquisas uma dramaturgia voltada para a infância e juventude. Por ser um grupo do interior e não ter o aporte que a capital tinha, o grupo abraçou o teatro como uma maneira de dizer sobre sua gente e de se manifestar culturalmente, buscando uma forma de valorizar o teatro feito para a infância e juventude no interior do Estado.

Como também, o fez considerando a existência de uma linha tênue entre os aspectos mais lúdicos aos mais trágicos do teatro, mostrando que as obras para infância e juventude podem verticalizar assuntos e torná-los dialéticos. Isto é, por meio de uma ação integradora que busque aproximar o campo artístico às demandas políticas da comunidade, procurando estabelecer conexões com assuntos sobre a diversidade, imaginação, liberdade, tristeza, além da inserção de temas transversais como racismo, machismo, sexismo, gênero, feminismo, entre outros. Como dialogar e construir pontes seguras para a discussão desses assuntos com as diferentes faixas etárias que compreendem a comunidade? Por que devemos verticalizar esses assuntos?

Partindo, sobremaneira, do princípio de Paulo Freire sobre uma educação emancipadora, libertadora e transformadora. A dialética e a verticalização desses aspectos são baseadas no diálogo e aliadas aos mecanismos da linguagem teatral de maneira potente, lúdica e pautada nas discussões que permeiam a sociedade. A partir de modelos de ação pela ótica da comunidade que se configura como um espaço de troca de saberes e ação social ao discutir assuntos pertinentes a ela. Pela perspectiva dialética, Marcia Pompeo Nogueira relata que:

Os trabalhos que pude pesquisar no meu doutorado, através de pesquisa de campo e bibliográfica, enquadram-se na abordagem dialógica do teatro para o desenvolvimento. Eles visam ao fortalecimento de comunidades, contribuindo enquanto um meio de comunicação entre diferentes setores da comunidade e enquanto forma de identificação e solução de problemas (NOGUEIRA, 2002, p. 70). 
Neste potencial dialético de discussão é possível engajar e contribuir para camadas de entendimento sobre determinados assuntos, permitindo a sociedade, como um todo, debater sobre eles a partir do empírico, fortalecendo o discurso em sua aplicabilidade do dia a dia na comunidade.

Dessa forma, o aprofundamento desses assuntos é apresentado, por exemplo, na tessitura de espetáculos como Alice do Grupo Faces Jovem que discute a questão de gênero na escola a partir da história de Alice que não se vê como Fernando e sofre por não se enquadrar nos padrões cis normativos impostos pela sociedade. Na escola sofre violência por parte dos outros estudantes e dos professores que são impedidos de discutir gênero na sala de aula. E do processo cênico Adeus de Maria do Grupo Primitivos que fala sobre o empoderamento feminino ao discutir as relações de poder e acesso numa história para infância e juventude que discute preconceito, o feminino e a possibilidade de uma segunda chance.

Com o alcance do grupo Teatro Faces dentro da comunidade e seu aumento em número de participantes, sentíamos uma necessidade de mostrar o que estava sendo produzido, pois os debates e as influências advinham da fala, visão de mundo e contexto cultural da cidade.

A ideia era trocar e perceber como o que estávamos discutindo e produzindo reverberaria na comunidade, de maneira geral. Com isso, Wanderson Lana, diretor do grupo, resolveu mediar quatro processos cênicos para a infância e juventude, trabalhando aspectos inerentes à faixa etária que compreendia aos jovens e adolescentes que faziam parte.

Assim, em 2007, cria-se a I Mostra de Teatro de Primavera do Leste, que passou a ser chamada de Festival de Teatro Velha Joana no ano seguinte. A mostra foi criada analisando o contexto cultural da cidade e do público - pais/responsáveis das crianças, jovens, adultos e crianças que acompanhavam as ações objetivando e emancipando os interesses da comunidade.

O nome Velha Joana refere-se à mais antiga habitante entre os primaverenses. Diz a tradição local que a "Velha Joana" - forma carinhosa de tratamento popular a uma senhora cujo nome 
completo é desconhecido - morou por todo o tempo de memória popular junto ao rio que recebe hoje seu nome, próximo a chácara 75, no bairro Parque Eldorado, na cidade de Primavera do Leste - MT. O Grupo de Teatro Faces resolveu homenagear essa simpática senhora que ajudava à todos com sua força e determinação diária, atribuindo seu nome ao festival que, atualmente, é um dos maiores festivais de teatro do Estado de Mato Grosso, o qual reúne grupos e coletivos do município, do Estado e de todo território brasileiro em 10 dias de festival, chegando a ter em sua programação aproximadamente 60 espetáculos/ processos cênicos.

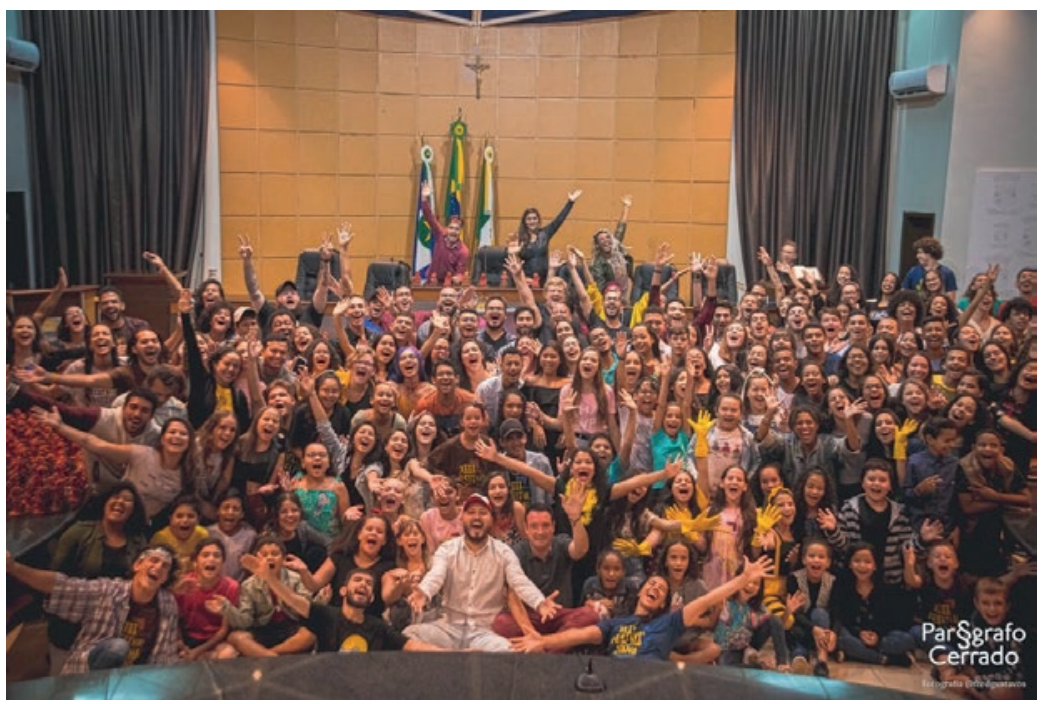

Figura 1: Encerramento da $13^{\circ}$ Edição do Festival Velha Joana.

Fonte: arquivo da autora.

Com o êxito da empreitada, sentíamos a necessidade de manter e expandir a ideia de produzir espetáculos considerando as diferentes faixas etárias de crianças e adolescentes que formávamos. Além de potencializar os conhecimentos adquiri- 
dos e desenvolver espaços que visavam à formação profissional desses jovens da comunidade.

No entanto, quando esses jovens - integrantes do Grupo de Teatro Faces - completavam 16/17 anos, muitos se viam obrigados a abandonar as aulas de teatro e procurar emprego por pressão familiar. Diante disso, o grupo buscou soluções para contornar essa situação e fundou em 2008 a Escola de Teatro Faces a fim de atender toda a comunidade primaverense entre crianças, jovens e adultos e promover/contribuir financeiramente com parte das famílias desses jovens. A partir desse momento, o Grupo se encaminhava para um teatro profissional e a Escola se tornava um espaço com o intuito de preparar uma base que mantivesse um corpo de atores/artistas para a continuidade do fazer teatral no município, fomentando o surgimento de outros grupos.

\section{ATRAVESSAR A COMUNIDADE: A PREFERÊN- CIA PELA DESCENTRALIZAÇÃO DA ESCOLA DE TEATRO}

Após muito diálogo e negociações com o poder público, Wanderson Lana conseguiu através da Coordenação de Cultura, vinculada à antiga Secretaria de Educação, Cultura, Esporte e Lazer contratar dois estagiários/bolsistas - não tinha emprego para todos naquele momento, mas essa ação era o início de uma parceria vindoura - para lecionarem oficinas de teatro no município por meio do projeto Escola de Teatro Faces.

Primeiramente, no ano inicial da escola eram apenas dezoito alunos divididos em duas turmas no espaço do Centro Cultural. Depois, timidamente, passamos também a ministrar oficinas de teatro em algumas instituições escolares do município e projetos sociais. A ideia era convidar alunos para fazerem oficinas de teatro no contraturno escolar duas vezes por semana por uma hora e meia cada aula. 
Com a chegada e auxílio do Projeto Pontos de Cultura ${ }^{4}$ em 2009 do Governo Federal - inclusive, época em que respirávamos arte e tínhamos um pouco de dignidade neste país - juntamente com o apoio da Prefeitura Municipal de Primavera do Leste, a escola passou a atender cerca de 230 alunos/alunas e no ano seguinte já contava com 635 , ou seja, mais de $1 \%$ da comunidade estavam em aulas/oficinas de teatro. Com o plano pedagógico de descentralização para garantia do acesso, vimos uma possibilidade de fortalecer as práticas artísticas na infância e juventude da cidade.

Entendemos que era necessário fortalecer a proposta pedagógica e ampliar os polos de atendimento (mais de 10 lugares diferentes) onde a Escola de Teatro Faces atenderia as diferentes comunidades/realidades que se estabeleciam na cidade. A cidade é composta por pessoas de diferentes classes e marcadores sociais, por ser um município de imigrantes do sul e, majoritariamente, do Maranhão e Bahia, o que torna a cidade plural em suas manifestações culturais.

Assim, a escola tem em seu corpo discente alunos de diferentes regiões, muitos em vulnerabilidade social advindos de bairros periféricos, além de alunos da zona rural que não têm acesso à cidade e aos bens culturais devido a distância. Ademais, na medida do possível, busca um equilíbrio entre esses territórios e sujeitos, gerando potentes deslocamentos internos e configurando experiências únicas dentro de uma heterogeneidade de pessoas que compõem a comunidade.

Hoje a denominada Escola Municipal de Teatro com o projeto pedagógico da Escola de Teatro Faces continua se organizando de maneira descentralizada, atendendo tanto a zona urbana como a zona rural, inserida nas comunidades e principalmente, atuando nos bairros, regiões onde se concentra a população em situação de vulnerabilidade social. A escola atende cerca de 410

40 projeto de Ponto de Cultura de Mato Grosso surgiu em 2009, quando o MinC passou a executar um convênio com a secretaria de Estado de Cultura. Em Mato Grosso são 35 pontos de Cultura, sendo 11 na capital e 24 em outros municípios do estado que atuam em diferentes áreas. Disponível em: http://www.facesdecultura.com/p/pontos-de-cultura/html. Acesso em: 03 de abril de 2020. 
alunos anualmente, entre crianças, jovens e adultos em 14 polos e apresenta uma média de 60 espetáculos por ano totalizando os dois semestres.

Com as parcerias públicas do município e do governo federal, potencializamos o alcance das ações da escola, aumentando os atendimentos diretos e indiretos de maneira volumosa. Entendemos aqui como atendimentos diretos aqueles nos quais a criança e/ou o adolescente é o sujeito beneficiado diretamente através das oficinas. Por outro lado, entendemos os atendimentos indiretos como aqueles nos quais a população, de modo geral, é beneficiada, pois está tendo acesso aos processos produzidos na forma de apresentação e intervenções artísticas.

Desde o princípio o intuito da escola era gerar possibilidades de os alunos/alunas aprenderem e trocarem conhecimentos a partir da montagem de um espetáculo semestralmente que fosse cunhado nas problemáticas, realidades e vontades de cada comunidade/polo que a escola atendia. E a partir disso, pudessem ter acesso ao processo de construção e confecção de um figurino, cenário, desenho e execução da luz e demais elementos que constroem um processo cênico ancorado em uma pedagogia do teatro. Ao passo que pudessem compreender e desenvolver suas próprias criações, partindo do pressuposto de que cada aluna/aluno constrói suas reflexões a partir de um registro sobre suas experiências de forma absorta, transcendendo sua autoria nas criações e inaugurando uma ação teatral como um encontro com sua própria estética.

Sobre o Teatro com a comunidade Marcia Pompeo Nogueira elucida que:

O trabalho teatral parte de uma investigação de uma determinada comunidade para a criação de um espetáculo. Tanto a linguagem, o conteúdo - assuntos específicos que se quer questionar - ou a forma - manifestações populares típicas - são incorporados no espetáculo. A ideia de vinculação a uma comunidade específica estaria ligada à ampliação da eficácia política do trabalho (NOGUEIRA, 2007, p. 79). 
Por isso, a pedagogia de ensino do teatro da Escola Municipal de Teatro - Projeto: Teatro Faces também é voltada para a introdução à interpretação, expressão corporal e também vocal dos alunos. Com uma proposta de ensino/aprendizagem que busca uma horizontalidade de ensino, com o equilíbrio de vozes entre o oficineiro/professor e o aluno na construção de um trabalho onde espectadores e os realizadores dos processos cênicos equilibram-se nas discussões, prezando pelos atravessamentos, pela história de vida e de como essas pessoas - aprendizes da escola de teatro - pensam o mundo.

Assim, o princípio de horizontalidade de ensino, caminha para um espaço de sensibilização, compartilhamento de ideias, troca de pontos de vistas com as crianças, jovens e adultos como uma emancipação social entre o educador e o educando que veem no processo educativo uma ponte para a escuta e construção igualitária “[...] em que ambos comunidade e facilitadores pesquisam a comunidade na busca de temas significativos que podem estar na base de processos teatrais conjuntos" (FREIRE, 1977 apud NOGUEIRA, 2007, p. 80).

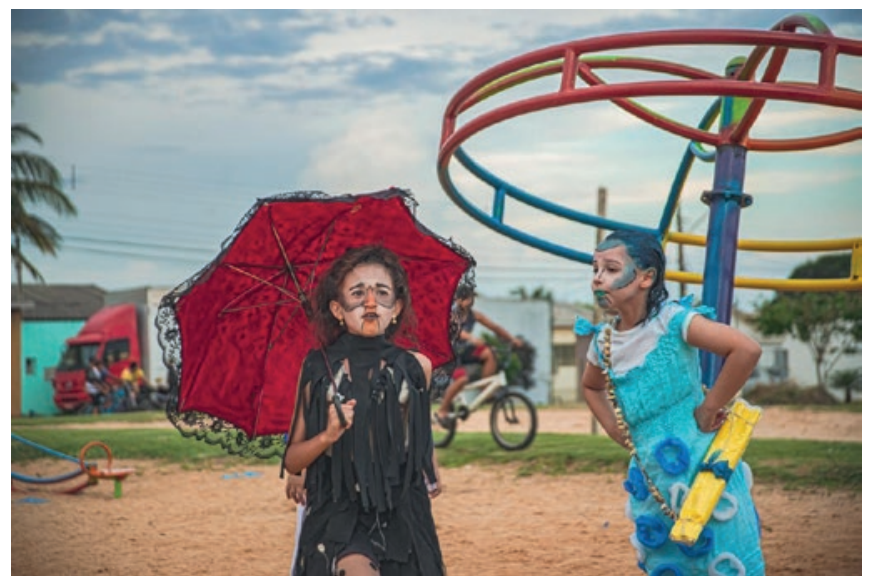

Figura 2: Apresentação do espetáculo Eu Chovo, Tu Choves, Eles Chovem da turma I do polo Centro Cultural da Escola Municipal de Teatro.

Fonte: arquivo da autora. 
Sobretudo, a escola tem a finalidade de difundir o fazer artístico e discutir as questões sociais necessárias à atualidade, agregando dentro de seu plano de ensino as parcerias firmadas com o intuito de desenvolver as crianças e os jovens na sociedade, dando impulso a sua conscientização, protagonismo juvenil e formação cultural. Em uma linha condutora que segue a proposta dialógica do teatro que se desenvolve a partir de uma fundamentação teórica e experimentação prática, a qual está centrada na voz das pessoas que participam ativamente da construção dos processos cênicos na comunidade.

Portanto, é importante e relevante nos processos cênicos dentro da comunidade delinear caminhos para pesquisas considerando as diferenças e complementaridades dos distintos espaços e contextos sociais, constituindo parâmetros práticos e objetivos que favoreçam a reflexão da comunidade dentro dos espaços de experimentações.

Com um teatro aplicado em contextos onde a obra criada, e apresentada, tenha comunicação e impactos específicos para os seus participantes e plateias. Por isso, proporcionar possibilidades de formação, incide sobretudo, no desenvolvimento da comunidade em todos os aspectos da atividade criadora, oral, escrita, entre outras.

Através das minhas experiências como professora dentro da escola e atriz do grupo, percebo que uma das grandes virtudes de ser professora/artista é poder contribuir, trocar e permitir que sejamos dialeticamente diferentes e, ao mesmo tempo iguais, ou seja, que resignifiquemos a arte do diálogo para debater as necessidades e vontades da comunidade, potencializando e ampliando os diálogos entre territórios e sujeitos. Como diz o grande educador Paulo Freire "(...) a educação é comunicação, é diálogo, na medida em que não é a transferência de saber, mas um encontro de sujeitos interlocutores que buscam a significação de significados". (FREIRE, 1977, p. 69 apud MEIRELLES, 2015, p. 62). 


\section{TRANSGREDIR: AS POSSIBILIDADES DE CO- MUNICAÇÃO COM OUTROS SABERES}

O teatro na comunidade emerge das histórias que determinada comunidade quer contar, cujo interesse se tenta expressar através de suas indagações, e está diretamente ligado ao desvelar e transformar da sua realidade. Estar dentro da comunidade, ser parte integradora dela e participar ativamente da mesma, traz-nos uma oportunidade única de proximidade com o que a circunda e com as pessoas que a compõem. Uma comunidade forte e estruturada é capaz de erguer sonhos e edificá-los.

Marcia Pompeo Nogueira define com precisão o território dessas práticas que levam o teatro a determinados grupos, envolvendo a participação de pessoas comuns, suas histórias, lugares, desejos, prioridades e que são motivadas pelo desejo político de transformar, por meio do teatro, realidades individuais e coletivas.

Diante da realidade social de boa parte dos integrantes da comunidade que estavam nas aulas/oficinas de teatro, analisamos que após a finalização do ensino médio, muitos não tinham condições financeiras para se mudar do estado e realizar um curso técnico ou uma graduação na área do teatro para continuar seus estudos, visto que em Mato Grosso não tinha/não tem uma graduação presencial em teatro/artes da cena.

Assim sendo, com o romper das fronteiras e a suspensão que vínhamos construindo no ensino do Teatro no interior de Mato Grosso, promovendo mudanças na cultura e arte por meio do Grupo de Teatro Faces e da Escola Municipal de Teatro. Os alunos, professores e artistas trouxeram em 2011 para Primavera do Leste a primeira Graduação Semipresencial na Área das Artes Cênicas do Estado. O Teatro Faces teve uma importância expressiva nesse movimento "Trabalhando a base, fomentando o teatro dentro do ambiente escolar e fortalecendo o Teatro profissional no interior" (LANA, 2014, p. 19).

$\mathrm{E}$, dessa maneira, a universidade oportunizou a formação 
acadêmica de grande parte dos integrantes do grupo, além de pessoas interessadas na área da comunidade. As aulas eram em modelo semipresencial através de atividades na plataforma de ensino online, e os professores vinham de Brasília de 15 em 15 dias para os encontros presenciais que duravam um final de semana inteiro imerso em trocas e aprendizados a fim de desenvolver a parte prática.

Desse modo, o curso de Licenciatura em Teatro foi ofertado pela UNB (Universidade de Brasília) através do programa UAB (Universidade Aberta do Brasil) e formou os primeiros profissionais na área em Mato Grosso na cidade de Primavera do Leste em 2014. A segunda turma aconteceu na cidade de Barra do Bugres - me formei nessa turma em 2018 - e em 2020, o curso iniciou sua terceira turma e tem como polo a cidade de Cuiabá. Até hoje, infelizmente, o estado não possui uma graduação presencial em Artes Cênicas.

Para Nogueira (2002), a comunidade é responsável por criar brechas e ambientes para o desenvolvimento da mesma, pois "a comunidade não se define apenas em termos de localidade [...] É a arena onde as pessoas adquirem suas experiências mais fundamentais e substanciais da vida social, fora dos limites do lar" (COHEN, 1985, p.15 apud NOGUEIRA, 2007, p. 78).

\section{A POÉTICA DA COMUNIDADE - CONSIDER- AÇÕES FINAIS}

A comunidade é quem molda e transforma a sociedade. Pensar coletivamente é uma das armas mais poderosas que podemos ter. A Escola de Teatro Faces e o Grupo de Teatro Faces sempre abriram portas que nos conectavam com outros lugares, fazendo pulsar e expandir o fazer teatral a fim de colaborar para a pesquisa que é realizada no interior de Mato Grosso transgredindo o espaço da comunidade.

Foi através do teatro que pulsa em Primavera do Leste que pudemos acreditar e fortalecer o teatro de grupo. Foi aqui que crescemos como indivíduos, como artistas, que viajamos o mun- 
do e possibilitamos que outras pessoas pudessem ter o mesmo acesso. Do Teatro Faces surgiu o grupo Faces Jovem e o Grupo Primitivos e uma quarta geração do teatro na comunidade primaverense está se formando.

Por esses motivos, o foco principal aqui foi expor o contexto em que o Teatro Faces surgiu e reverberou na cidade com a criação da Escola Municipal de Teatro como forma de compartiIhar o mundo e se mover em um teatro a partir do engajamento de jovens com a prática teatral em contextos comunitários.

O teatro na comunidade gira em torno das histórias pessoais da comunidade, cujos interesses se tenta expressar e emerge diretamente de suas formas e materiais promovendo uma mudança social, a fim de desvelar e transformar sua realidade. Dá-se aí também o princípio da horizontalidade do ensino entre o professor e o aluno discutido por Paulo Freire e Marcia Pompeo e presentes nas estratégias pedagógicas da Escola Municipal de Teatro - Projeto: Teatro Faces.

Hoje, temos políticas públicas fortificadas para o teatro primaverense, e a Associação Cultural Teatro Faces promove além das oficinas de teatro, projetos de cinema, circo e formas animadas. Coordena a Escola Municipal de Teatro; garante trabalho para 15 instrutores/professores de teatro e promove três bolsas de estudo para jovens aprendizes de teatro.

Marcia Pompeo Nogueira foi uma figura feminina forte que alavancou muitos projetos importantes e nos fez olhar para o teatro que é produzido na periferia, na fronteira. Marcia entrou nos espaços do saber transformando, inevitavelmente, este campo do teatro na comunidade, realocando as questões, questionando, colocando novas questões para serem pensadas. Sem dúvidas alguma, seu apoio rompeu estruturas epistemológicas nos fazendo perguntar: Quais são as vozes que estão presentes na comunidade? Que experiências dialógicas são essas?

Assim, reconheço este trabalho como fruto de uma longa jornada de aprendizagem, discussões, afetos e atravessamentos artísticos trocados com a comunidade de Primavera do Leste. E, acredito no legado e nas experiências pedagógicas que Marcia Pompeo nos deixou como frutos para construir pontes de co- 
nhecimentos e possibilidades para o teatro na comunidade que acontece em cada canto do Brasil.

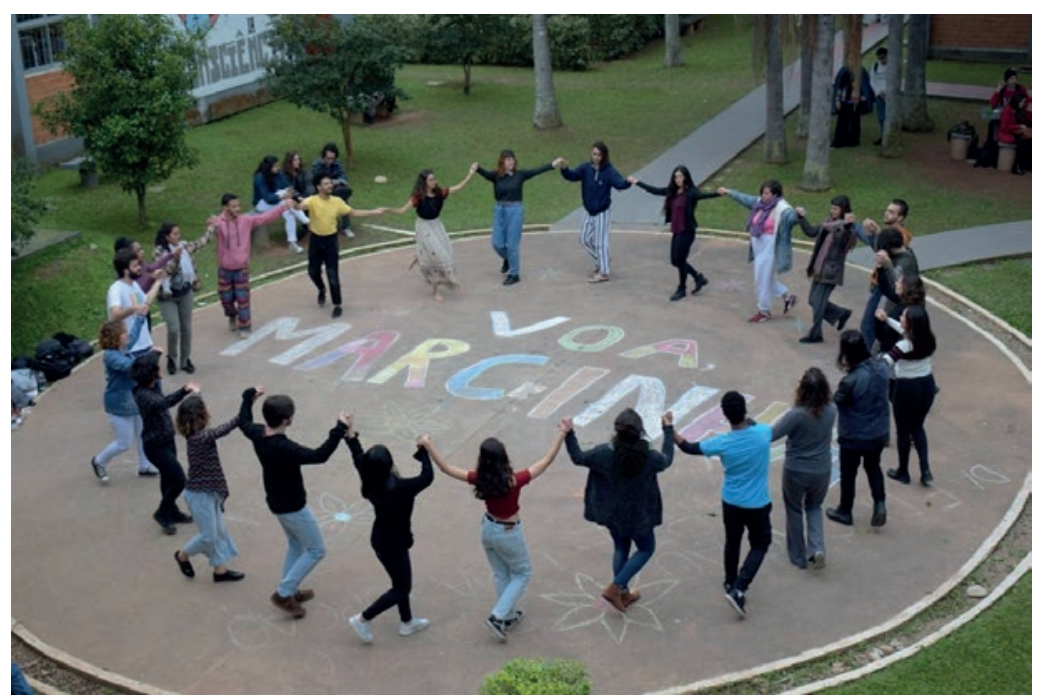

Figura 3: Homenagem dos alunos da $4^{\circ}$ fase de Licenciatura em Teatro, que integraram a última turma de graduação educadora na UDESC (2019). 


\section{REFERÊNCIAS}

NOGUEIRA, Marcia Pompeo. Tentando definir o Teatro na Comunidade. DAPesquisa, Florianópolis, v.2, n.4, p. 077-081, 2007.

NOGUEIRA, Marcia Pompeo. Buscando uma interação teatral poética e dialógica com comunidades. Urdimento 4. Universidade do Estado de Santa Catarina, 2002.

CABRAL. Yuri Lima. O espetáculo Alice: Pedagogia do Teatro em discussões de gênero com a juventude. 116 f. 2019. Dissertação (Mestrado em Teatro) - Universidade do Estado de Santa Catarina, UDESC, Florianópolis, 2019.

LANA, W. A. M. de. O menino e o céu: o trágico no teatro para a infância e juventude. 91f. 2014. Dissertação (Mestrado em Estudos de Cultura Contemporânea) - Universidade Federal de Mato Grosso, UFMT, Cuiabá, 2014. Disponível em:

http://www.facesdecultura.com/p/pontos-de-cultura/html. Acesso em: 03 de abril de 2020.

MEIRELLES, Renata. Território do Brincar - diálogo com escolas. São Paulo: Instituto Alana, 2015. 